\title{
FUSION REACTOR MATERIALS TESTING (DT FUEL)
}

by

Glenn À. Gerdin

\section{MASTER}

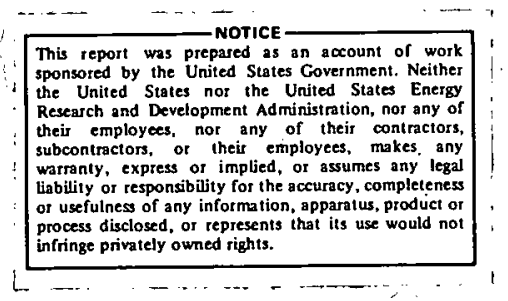




\section{DISCLAIMER}

This report was prepared as an account of work sponsored by an agency of the United States Government. Neither the United States Government nor any agency Thereof, nor any of their employees, makes any warranty, express or implied, or assumes any legal liability or responsibility for the accuracy, completeness, or usefulness of any information, apparatus, product, or process disclosed, or represents that its use would not infringe privately owned rights. Reference herein to any specific commercial product, process, or service by trade name, trademark, manufacturer, or otherwise does not necessarily constitute or imply its endorsement, recommendation, or favoring by the United States Government or any agency thereof. The views and opinions of authors expressed herein do not necessarily state or reflect those of the United States Government or any agency thereof. 


\section{DISCLAIMER}

Portions of this document may be illegible in electronic image products. Images are produced from the best available original document. 
FUSION REACTOR MATERIALS TESTING (DT FUEL)

\section{Introduction}

A rough model of a fusion reactor is shown in Fig. 1. Since neutrons in the DT reaction carry away $80 \%$ of the energy and are not confined by the magnetic field, the first wall will have to experience a high neutron flux $\left(5 \cdot 10^{13} \mathrm{n} / \mathrm{cm}^{2} \mathrm{sec}\right.$ or greater) for the heating of the blanket region to be sufficient for the thermal cycle of the reactor to be economic. Since tritium does not exist in nature it must be bred using the DT neutron and lithium in the blanket region (Fig. 2), lithium (a highly corrosive liquid metal) is usually chosen as the coolant for a DT fusion reactor. Thus the first wall, which must keep coolant and blanket materials from penetrating into the plasma region and poisoning the reacting plasma core, is in an extremely hostile environment. On the plasma side it is continually bombarded by neutrons, charged particles. and plasma radiation and on the blanket side it is in contact with a corrosive liquid at high temperatures.

Maintenance of the integrity of the lst wall in a fusion reactor represents a large portion of the maintenance costs. For UWMAK I, a 1 GW(e) Tokamak reactor designl, the stainless steel 1 st wall and blanket were estimated to need replacement every two years at a cost of $\$ 45$ million/yr. (The activation of the Ist wall and blanket structures by the neutrons make remote handling a necessity.) Thus the choice of a material which could greatly lengthen the period of lst wall integrity would be of great economic importance to fusion reactor technology and thus the necessity of a Fusion Energy Research Facility ${ }^{2}$ (FERF) to do fusion materials research becomes obvious. In the remainder of this paper the important first wall damage processes predicted to occur in fusion reactors will be reviewed, with the specific example of void swelling worked out in more detail. Since many of these processes are found to exist in the fuel rod cladding of liquid metal fast breeders a comparison of the phenomena in the two types of reactors will be presented to gain some historical perspective. From analysis of these damage phenomena the requirements for a FERF are stated. Finally a fusion product source, a hypocycloidal pinch, which is to be built at University of Illinois and which could scale up to a FERF, will be discussed.

1st Wall Damage Processes

The first wall damage processes predicted to occur ${ }^{2}$ are
1) void swelling
2) embrittlement
3) irradiation creep (non-uniform deformation)
4) corrosion by liquid metals
5) sputtering (by $\alpha$ particles and plasma ions)
6) blistering (by a particles and plasma ions) 


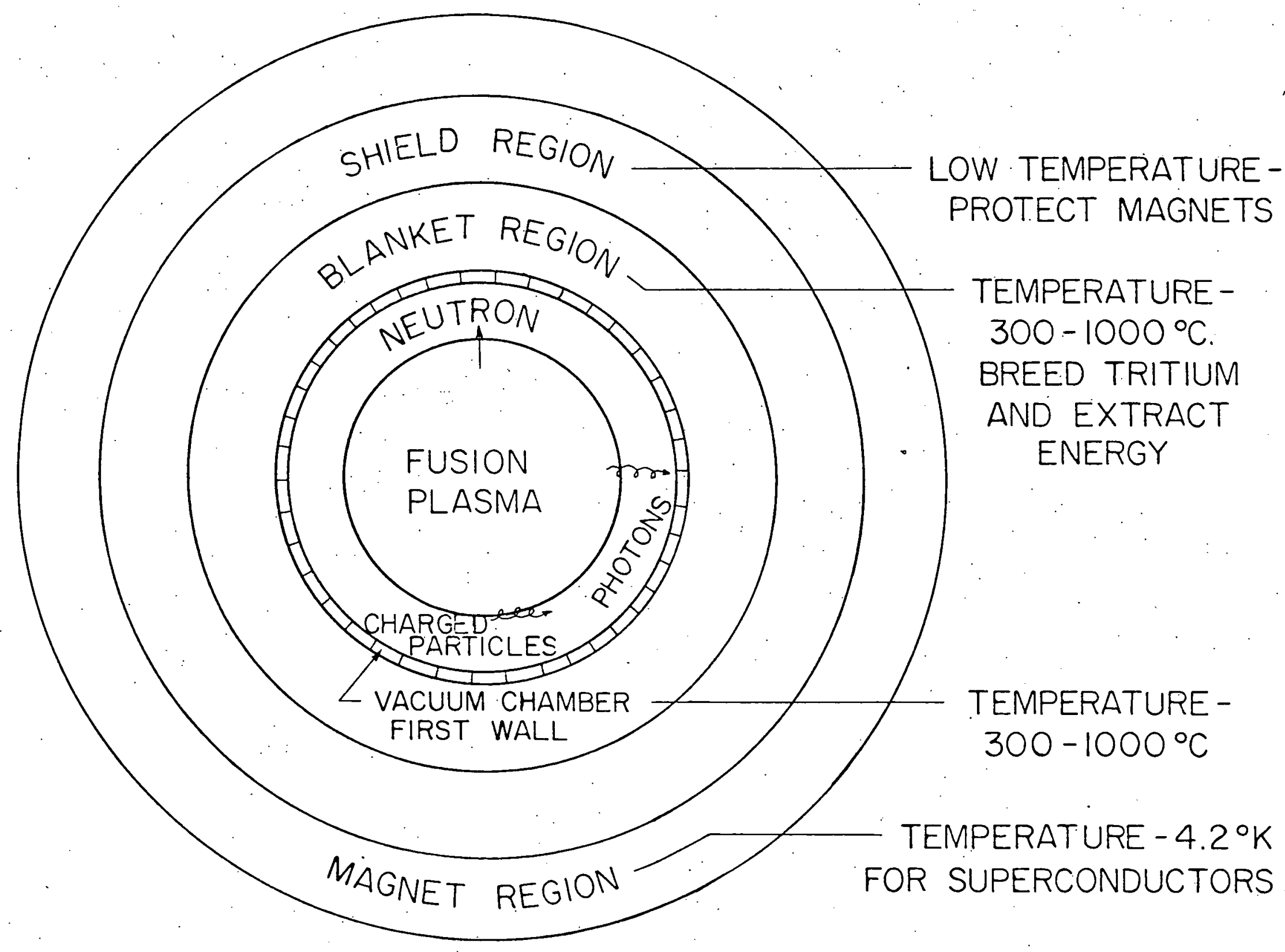




\section{FUSION REACTIONS}

Plasma:

$$
\begin{aligned}
D+D & \underset{50 \%}{\longrightarrow} T(1.01 \mathrm{MeV})+p(3.02 \mathrm{MeV}) \\
\underset{50 \%}{\longrightarrow} \mathrm{He}^{3}(.82 \mathrm{MeV})+n(2.45 \mathrm{MeV}) & \\
D+T & \rightarrow \mathrm{He}^{4}(3.5 \mathrm{MeV})+n(14.1 \mathrm{MeV}) \\
D+H e^{3} & \rightarrow \mathrm{He}^{4}(3.7 \mathrm{MeV})+p(14.7 \mathrm{MeV})
\end{aligned}
$$

\section{Blanket:}

$\mathrm{n}+\mathrm{Li} \rightarrow \mathrm{T}+\mathrm{He}^{4}+4.8 \mathrm{MeV}$
$\mathrm{n}(5 \mathrm{MeV})+\mathrm{Li}^{7} \longrightarrow \mathrm{T}+\mathrm{He}^{4}+\mathrm{n}$

Fig. 2 
The first three are caused by neutrons ${ }^{3}$ producing displacements and transmutations of the Ist wall atoms. Hence these processes cannot be simulated by charged particle accelerators and therefore a FERF would be required. Since void. swelling is viewed to be the most important of these it is considered here in detail.

\section{Void Swelling}

Neutrons bombarding of metals knock atoms out of the lattice creating voids (Fig. 3) in the lattice and interstitial atoms. At low temperatures the voids and interstitial atoms can't migrate very well and so the metal swells until the strain becomes too great and the metal ruptures (Fig. 4). However, at temperatures at which either a fusion reactor lst wall and/or breeder reactor cladding. (Fig. 5) operate $\left(2500^{\circ} \mathrm{C}\right)$ the mobility of the voids and interstitial atoms is high enough so sufficient numbers of voids and interstitials can recombine to make the swelling very minor. Thus until 1967 only embrittlement was thought to be a problem in the cladding of breeder fuel rods and this could be circumvented by careful design.

The fast neutron fiux in a breeder reactor al so produces helium and hydrogen gas through transmutation reactions $[(n, \alpha)$ and $(n, p)]$ with the atoms of the cladding lattice. These gas atoms can then fill the lattice voids produced by the fast neutrons and prevent void-interstitial annihilation (Fig. 6). These reactions don't occur to any extent in the light water reactors because the neutron energies are too low for the transmutations to occur, so little experience in this phenomenon is available. 4 In experiments in the experimental breeder reactor, EBRII, this type of void swelling was only found to occur in stainless steel after $10^{22}$ neutrons $/ \mathrm{cm}^{2}$ had passed through the sample. This amount of fast neutron. fluence to cause swelling puts a high neutron yield requirement on any FERF device for adequate materials testing. But void swelling could limit lst wall of a fusion reactor to less than two years, so this testing must be done.

A major uncertainty in all the analysis of void swelling is that the neutron energy dependence of the reaction cross section for $[n, \alpha]$ and $[\mathrm{n}, \mathrm{p}]$ reactions is poorly known. 4 Since a fusion reactor has a much 'harder' neutron energy spectrum than the EBRII' (see Fig. 7), one may not be able to extrapolate EBRII data to fusion reactor first wall conditions.. An example of the possible differences in these reactions between EBRII and a fusion reactor is shown in Table I for various 1 st wall materials. 5 These differences make it apparent that a FERF is necessary to be able to do adequate materials testing and that such a facility should be able to irradiate a material to at least $10^{22}$ neutrons $/ \mathrm{cm}^{2}$ within a year's time to speed up the results, although, as we shall see, information on the $(n, \alpha)$ and $(n, p)$ reactions in various materials could be gotten with considerably less neutron fluence.

The Hypocycloidal Pinch as a FERF

At the University of Illinois, members of the Nuclear Engineering faculty 6 have proposed to build a device which may scale up to a FERF. The device is called a hypocycloidal pinch ${ }^{7}$ (HCP) and was recently invented 


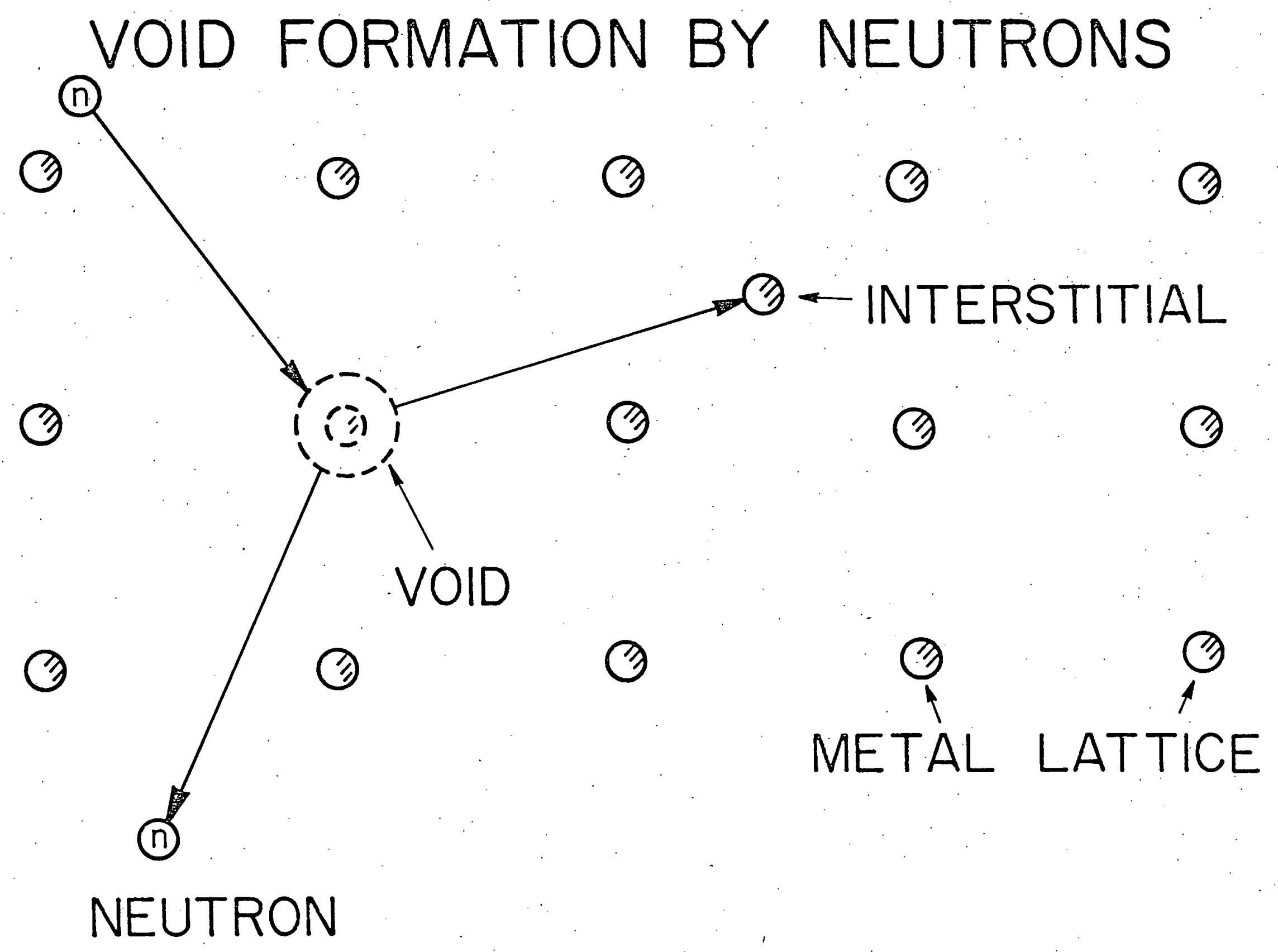

Fig. 3 


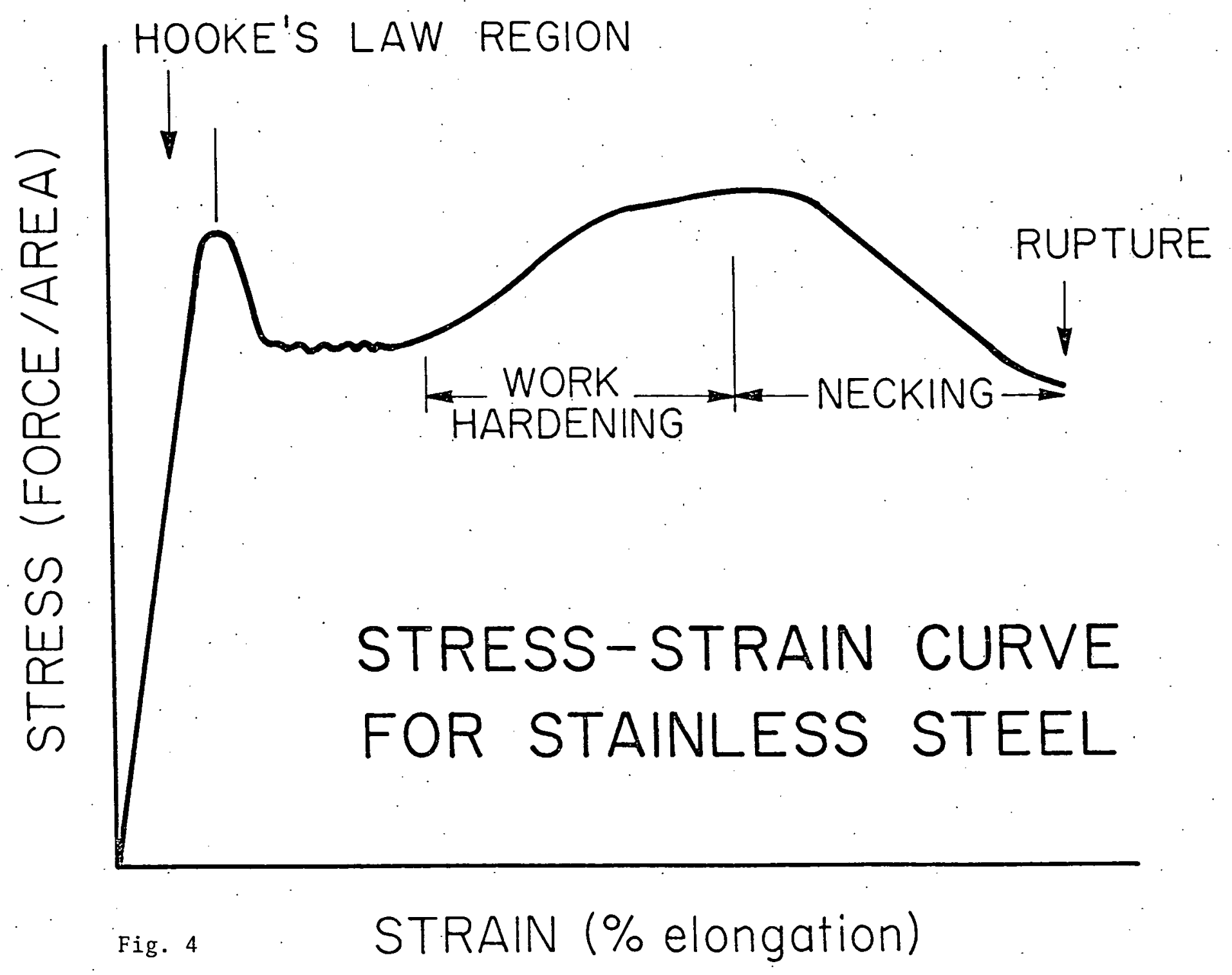




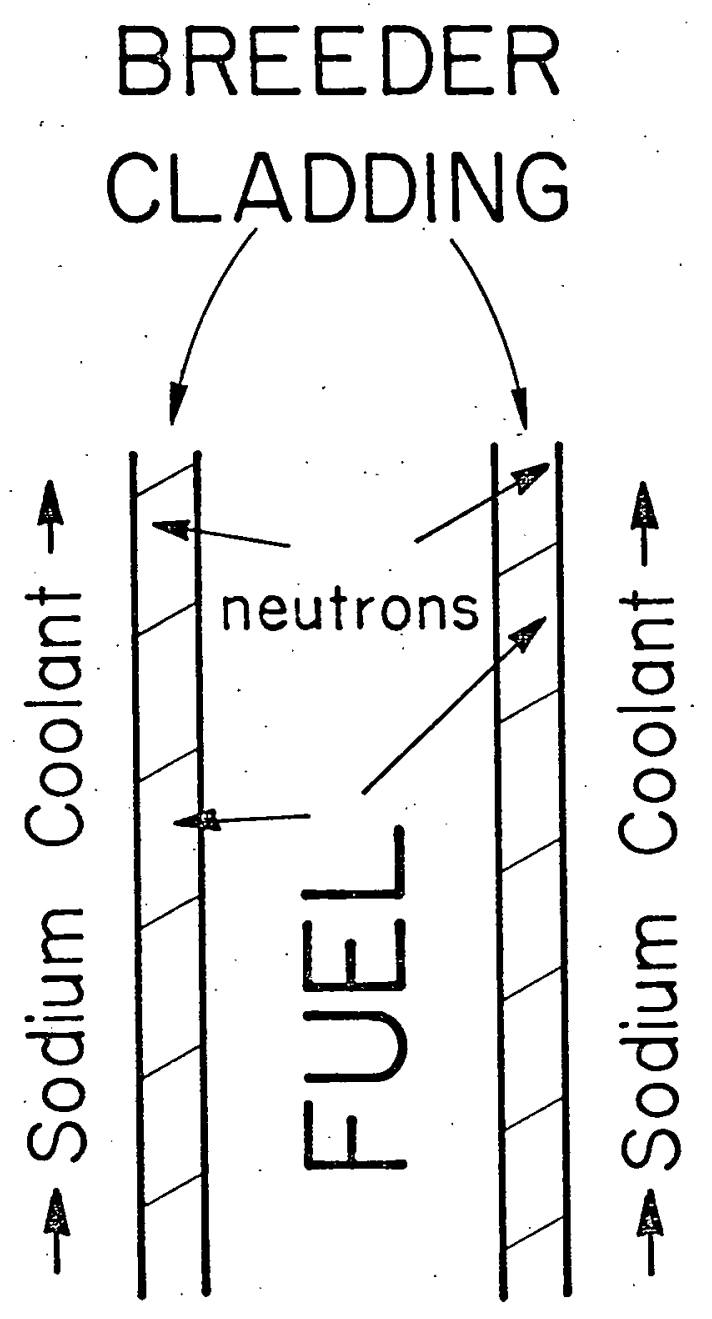

FUSION REACTOR $I^{\text {ST }}$ WALL

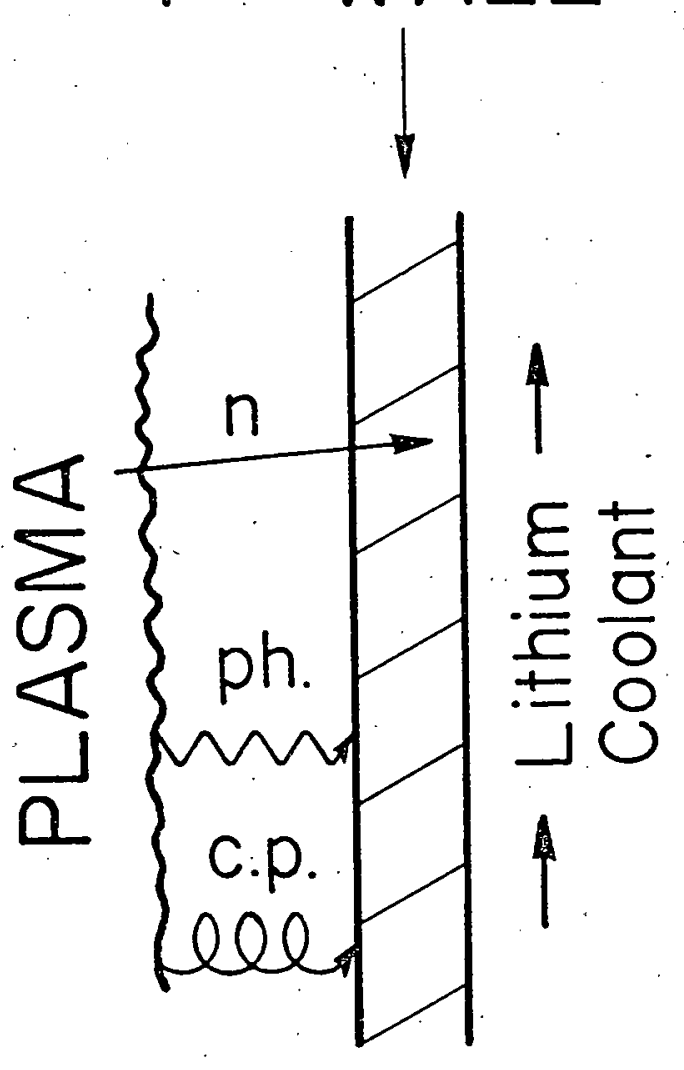

Fig. 5: Environment of Cladding and 1st Wall 
○

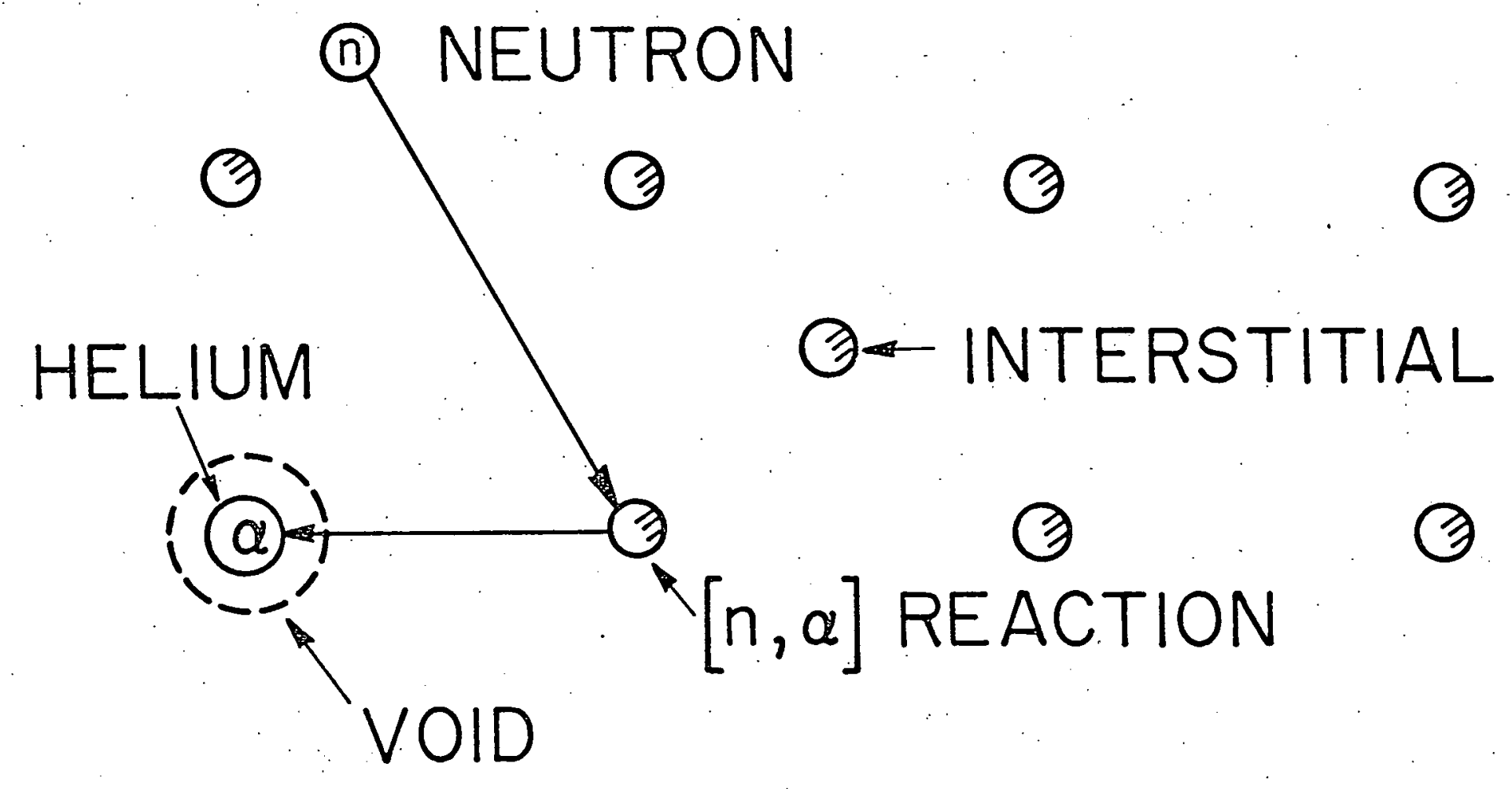

○

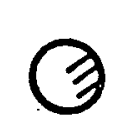

○

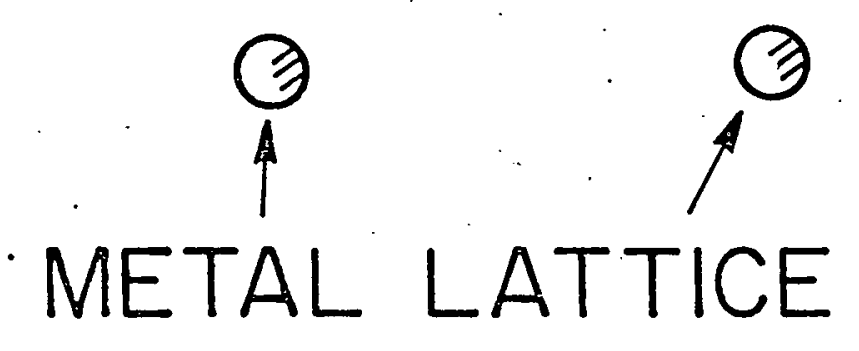

Fig. 6: Void Swelling \& Transmutations 


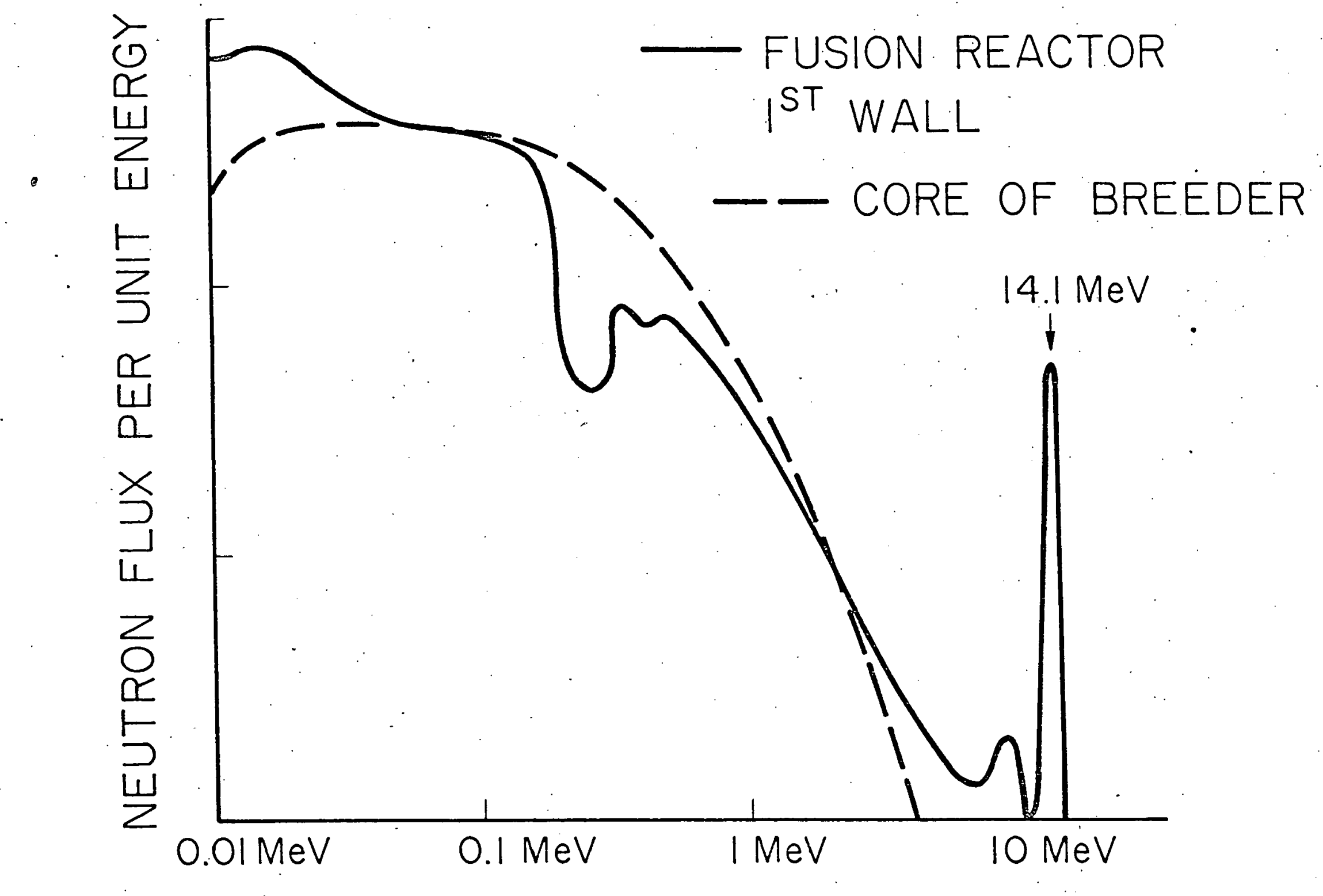

Fig. 7: Neutron Flux Energy Spectra 
TABLE I

Transmutation Reaction Rates in the First Wall of a Fusion Reactor loaded to $1 \mathrm{MW} \mathrm{cm}^{2}$ and in the core of a Fast Reactor (reference 13)

\begin{tabular}{|c|c|c|c|}
\hline \multirow{2}{*}{ Element } & \multirow{2}{*}{ Reaction } & \multicolumn{2}{|c|}{ Reaction Rate } \\
\hline & & $\begin{array}{c}\text { Fusion Reactor } \\
\text { ppm/year }\end{array}$ & $\begin{array}{c}\text { Fast Reactor } \\
\text { ppm/year }\end{array}$ \\
\hline $\begin{array}{l}\mathrm{Nb} \\
" \\
" \\
"\end{array}$ & $\begin{array}{l}(n, 2 n) \\
(n, \gamma) \\
(n, p) \\
(n, \alpha)\end{array}$ & $\begin{array}{r}520 \\
980 \\
40 \\
12\end{array}$ & $\begin{array}{r}7 \\
6000 \\
17 \\
2\end{array}$ \\
\hline $\begin{array}{l}\text { Mo } \\
" \\
" \\
"\end{array}$ & $\begin{array}{l}(n, 2 n) \\
(n, \dot{\gamma}) \\
(n, p) \\
(n, \alpha)\end{array}$ & $\begin{array}{r}1560 \\
990 \\
82\end{array}$ & $\begin{array}{r}35 \\
5800 \\
19 \\
2\end{array}$ \\
\hline $\begin{array}{l}\text { Fe } \\
" \\
" 1 \\
"\end{array}$ & $\begin{array}{l}(n, 2 n) \\
(n, \gamma) \\
(n, p) \\
(n, \alpha)\end{array}$ & $\begin{array}{r}440 \\
42 \\
151 \\
128\end{array}$ & $\begin{array}{r}2 \\
410 \\
89 \\
3\end{array}$ \\
\hline $\begin{array}{l}\mathrm{Ni} \\
" 1 \\
"\end{array}$ & $\begin{array}{l}(n, 2 n) \\
(n, \gamma) \\
(n, p) \\
(n, \alpha)\end{array}$ & $\begin{array}{r}10 \\
54 \\
570 \\
28\end{array}$ & $\begin{array}{r}1 \\
634 \\
1568 \\
72\end{array}$ \\
\hline $\begin{array}{l}\text { Cr } \\
" \\
"\end{array}$ & $\begin{array}{l}(n, 2 n) \\
(n, \gamma) \\
(n, p) \\
(n, \alpha)\end{array}$ & $\begin{array}{r}230 \\
40 \\
160 \\
150\end{array}$ & $\begin{array}{r}3 \\
308 \\
53 \\
3\end{array}$ \\
\hline $\begin{array}{l}\mathrm{Zr} \\
" 1 \\
" 1 \\
"\end{array}$ & $\begin{array}{l}(n, 2 n) \\
(n, \gamma) \\
(n, p) \\
(n, \alpha)+ \\
(n, n, \alpha)\end{array}$ & $\begin{array}{r}990 \\
77 \\
51 \\
5\end{array}$ & $\begin{array}{r}20 \\
587 \\
2 \\
0.05\end{array}$ \\
\hline V. & $\begin{array}{l}(n, p) \\
(n, \alpha)+ \\
(n, n \alpha)\end{array}+$ & $\begin{array}{l}49 \\
26\end{array}$ & $\begin{array}{l}13 \\
0.4 \\
0.003\end{array}$ \\
\hline${ }^{\mathrm{T}} \mathrm{T}$ & $\begin{array}{l}(n, p) \\
(n, \alpha)\end{array}$ & $\begin{array}{r}110 \\
32\end{array}$ & $\begin{array}{l}42 \\
10\end{array}$ \\
\hline
\end{tabular}


at NASA Langley. In the remainder of this paper the possibilities of an HCP as a FERF will be discussed.

The HCP belongs to a family of plasma devices that create and maintain a plasma by the pinch effect through a fast-rising, imploding current sheath. The other members of this family are the theta pinch, the $z$ pinch, and the dense plasma focus. The Hypocycloidal pinch is a combination of a $z$ pinch and a Filippov-type dense plasma focus. The common characteristic for all pinch devices is that the magnetic bottle is established very quickly: the order of a microsecond, and that the plasma contained within is quite dense: $1016 / \mathrm{cc}-10^{19} / \mathrm{cc}, \mathrm{T} \sim 1 \mathrm{KeV}$.

Unfortunately, the magnetic bottle does not remain intact for very long in pinch devices because of plasma instabilities and other problems. End losses and instabilities have prevented long confinement in theta pinches. $Z$ pinches have never been seriously considered for a large scale confinement device because of instabilities, although they have other practical uses. Plasma foci do have the best record for density-confinement and temperature, but, scaling to a CTR breakeven device seemed uncertain. The HCP appears to have the most promise with its ability to produce hot, dense, DPF-like plasmas that appear to be grossly MHD stable.

The operation of the HCP is shown in figure 8 . The capacitor bank is charged to a high voltage and the switch is thrown putting. a high voltage on the center electrode causing a cylindrical current $I_{0}$ to form both above and below the central electrode. The magnetic fields produced by this current cause it to rapidly implode into the central shaded region sweeping the ionized gas atoms (the chamber is filled with gas before the pulse) before it much in the manner of a snowplow ${ }^{7}$. Using the snowplow model 8 , the implosion speed, $v$, is found to scale as

$$
\frac{\mathrm{v}}{\mathrm{v}_{\mathrm{o}}}=\left(\frac{\mathrm{V}}{\mathrm{V}_{\mathrm{o}}}\right)^{1 / 2}\left(\frac{\mathrm{L}_{\mathrm{o}}}{\mathrm{L}}\right)^{1 / 2}\left(\frac{\mathrm{p}_{\mathrm{o}}}{\mathrm{p}}\right)^{1 / 4}
$$

where $V$ is the capacitor voltage, $L$ is the system inductance and $p$ is the initial fill pressure of the chamber. Since this model predicts the final temperature, $\mathrm{T}_{\mathrm{f}}$, to scale as $\mathrm{v}^{2}$, we have

$$
\frac{\mathrm{T}_{\mathrm{f}}}{\mathrm{T}_{\mathrm{f}_{\mathrm{o}}}}=\frac{\mathrm{V}}{\mathrm{V}_{\mathrm{o}}} \frac{\mathrm{L}_{\mathrm{o}}}{\mathrm{L}}\left(\frac{\mathrm{p}_{\mathrm{o}}}{\mathrm{p}}\right)^{\mathrm{I} / 2}
$$

The reaction rate goes as $T_{f} 4.5$ for $D D$ reactions in this range and the yield should scale as $V^{4.5}$. This is close to that scaling observed in dense plasma focus experiments (Figure 9), a device which is very similar to the HCP. * The 'density using this model goes as $\mathrm{pR}_{0}^{2}$ where $\mathrm{R}_{\mathrm{o}}$ is the radius of the HCP chamber. Using 'snowplow' scaling, the yields shown in Table II are predicted for HICUP, or HCP at U. of I.. HICUP is designated by number

* The HCP has not been around long enough for these types of measurements to have been performed on it. 

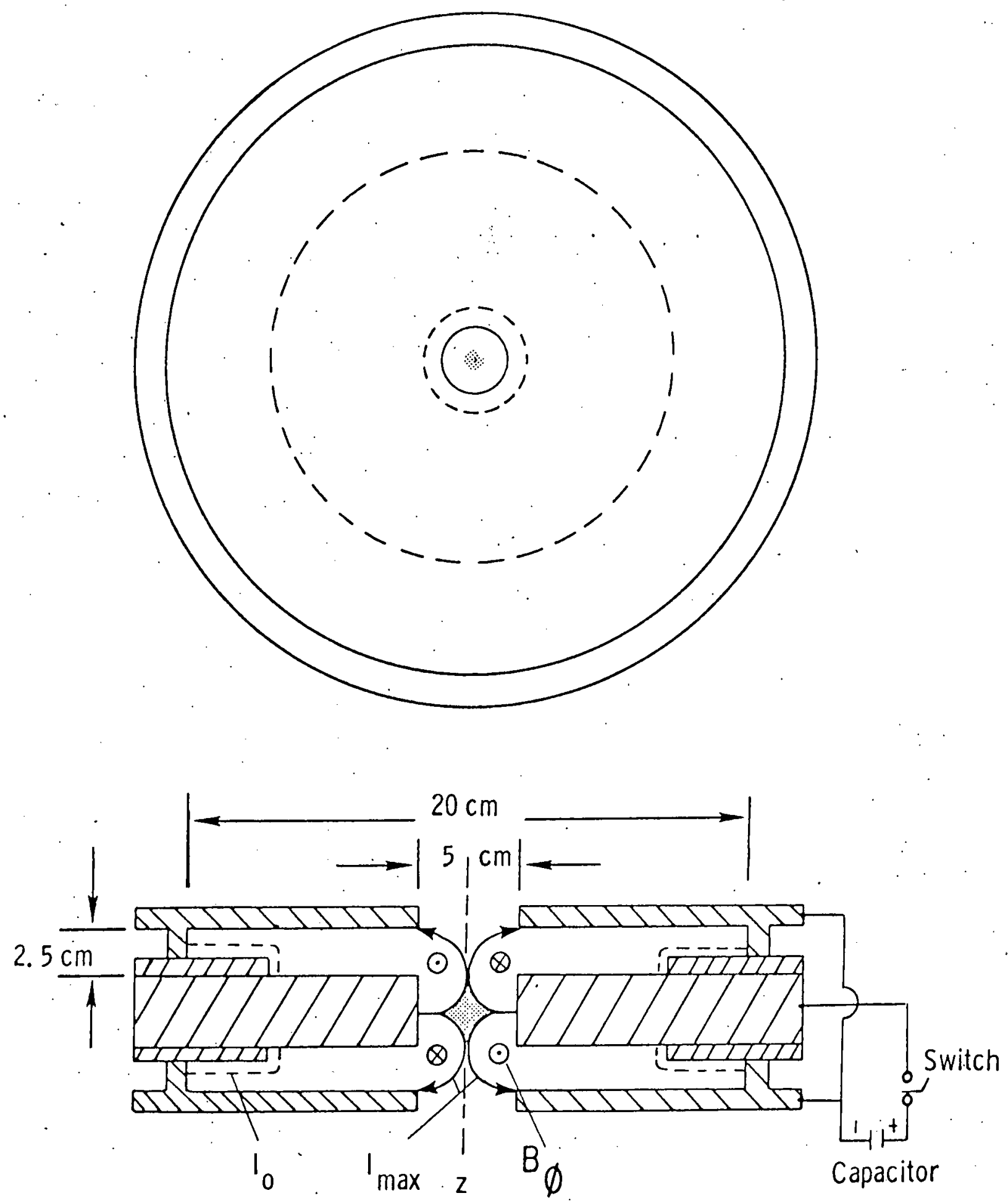

Figure 8 - Plan view of the cross section of hypocycloidal-pinch apparatus. 
Los Alamos Data for a 212-kJ Machine. Line in (a) represents $\sim V^{5} \sim I^{5}$ and lines in (b) represent $\sim E^{2} \sim V^{4} \sim I^{4}$.
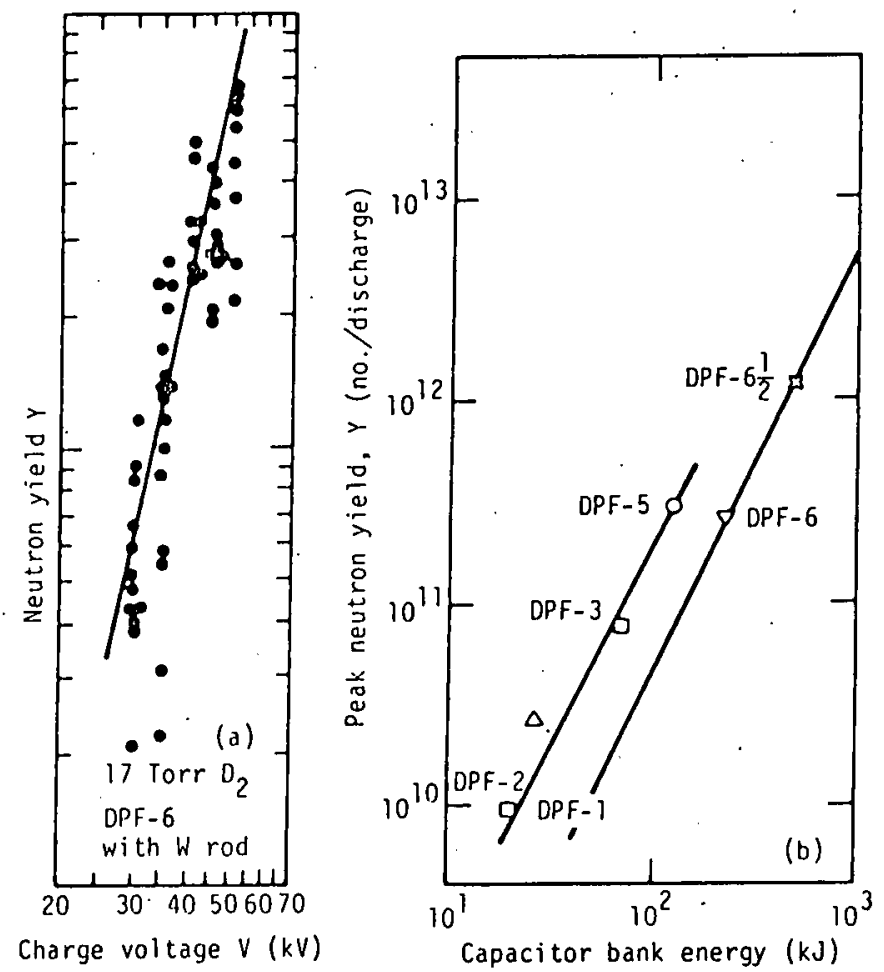

Figure 9. 
TABLE II - 'SNIOUPLOW' SCALING OF HCP

\begin{tabular}{|c|c|c|c|c|}
\hline PARAMETER & N.A.S.A. LangLEY & HICIP 1 & HICIP 2 & HICUP 3 \\
\hline V & $19 \mathrm{kV}$. & $50 \mathrm{k} !$ & $50 \mathrm{kV}$ & $100 \mathrm{kV}$ \\
\hline$L$ & $24 N$ & $20 \mathrm{NH}$ & $12 . N H$ & $12 \mathrm{NH}$ \\
\hline $\begin{array}{c}T_{I} \\
\text { YIELD DDN } \\
\text { (NO CROWBAR) }\end{array}$ & $\begin{array}{l}1 \mathrm{kEV} \\
3 \cdot 10^{8}\end{array}$ & $\begin{array}{l}2.6 \mathrm{kEV} \\
2 \cdot 10^{10}\end{array}$ & $\begin{array}{l}4.3 \mathrm{kE} / \\
9 \cdot 10^{10}\end{array}$ & $\begin{array}{l}8.7 \mathrm{kEV} \\
7 \cdot 10^{11}\end{array}$ \\
\hline $\begin{array}{l}\text { YIELD DDN } \\
(300 \text { uSEC CROWEAR })\end{array}$ & $3 \cdot 10^{10}$ & $3 \cdot 10^{12}$ & $2.5 \cdot 10^{13}$ & $2 \cdot 10^{14}$ \\
\hline $\begin{array}{l}\text { YIELD DTN } \\
\text { (NO CRONBAR) }\end{array}$ & $3.2 \cdot 10^{10}$ & $9 \cdot 10^{11}$ & $6 \cdot 10^{12}$ & $6 \cdot 10^{13}$ \\
\hline $\begin{array}{l}\text { Y'IELD DTN } \\
(300 \text { USEC CROWBAR) }\end{array}$ & $1.2 \cdot 10^{12}$ & $2 \cdot 10^{14}$ & $1.7 \cdot 10^{15}$ & $\begin{array}{l}1.6 \cdot 10^{16} \\
(0 \sim, 28)\end{array}$ \\
\hline
\end{tabular}


1, 2, 3 indicating the initial device of $\mathrm{L} \sim 20 \mathrm{nH}, \mathrm{V} \sim 50 \mathrm{kV}$, the next. improvement in. Switches to $\mathrm{L} \sim 12 \mathrm{nH}$ and the entire system upgrade to $\mathrm{V}=100 \mathrm{kV}$.

Since the HCP plasma is stable, limited at present only by the current reversal time, the possibility exists for greatly extending the duration of the plasma burn by a method known as 'crowbarring'. In Figure 10 this method is illustrated. In the normal operation (Figure.10a), the HCP device acts as an underdamped LC circuit with the current reversal time given by $\Pi(L C)^{1 / 2}$. Since making $L$ larger lowers the implosion speed and making $C$ larger increases the expense, not much can be done to lengthen the burn period. However, if the bank can be shorted out by switch $\mathrm{S}_{2}$ when the voltage across the capacitor is zero, the magnetic energy can no longer return to the capacitor bank as electrostatic energy $\left(1 / 2 \mathrm{CV}^{2}\right)$ and so this energy can only dissipate in the circuit resistance resulting in a long period $(\sim \mathrm{L} / \mathrm{R})$ before current reversal occurs. This time would be about $300 \mu \mathrm{sec}$ for the proposed HICUP device giving a much longer burn period assuming the plasma remains stable. Thus if 'snowplow' scaling holds and if crowbarring were successful the large yields of neutrons with $D-T$ fill gas become possible (see Table II). In fact, this device would be within $25 \%$ of energy breakeven.

The requirements for a FERF device are shown in Table III with the number of D-T HICUP 3 pulses necessary. Since with crowbarring no current reversal occurs the 1 ifetime of the capacitor bank could be extended to at least $10^{4}$ shots, surface studies, transmutation reaction rate studies, defect studies could be performed. But unless more favorable scaling occurs*, actual void swelling would not be observed.

However, the macroscopic transmutation reaction rate studies, [n,p] $[n, \alpha]$ so important in void swelling could be performed in a near term device such as HICUP 1 . As an example, take the reaction $56^{\mathrm{Fe}}(\mathrm{n}, \mathrm{p}) 56_{\mathrm{Mn}}$. The ${ }^{56} \mathrm{Mn}$ nucleus is in an excited state and decays by giving off a 0.853 $\mathrm{MeV} \gamma$ ray with a half life, $\tau$, of $2.57 \mathrm{hrs}$. By measuring the decay rate (by counting the $\gamma^{\prime} s$ ) after a sample has been irradiated by an HCP of known yield, one can get a measurement of the macroscopic cross-section for this ( $n, p)$ reaction with a realistic fusion neutron energy spectrum. The number of ${ }^{56} \mathrm{Fe}$ in one $\mathrm{cm}^{3}$ of stainless steel, $\rho_{\mathrm{ss}}$, is $8 \cdot 10^{22}$ and the cross-section, $\sigma[\mathrm{n}, \mathrm{p}]$, for this reaction is roughly $0.5 \cdot 10^{-1}$ barns so the probability of this reaction for a sample of thickness $d$ is

$$
\mathrm{P}_{[\mathrm{n}, \mathrm{p}]}=\rho_{\mathrm{ss}} \sigma_{[\mathrm{n}, \mathrm{p}]}^{\mathrm{d}} \text { (per incident neutron) }
$$

The decay rate, $R$, after irradiation is

$$
R \cong \frac{f_{n} P[n, p]}{\tau},
$$

* In small DPF devices the neutron yields scales as $V^{8}$ (ref. 9). 
10 a)

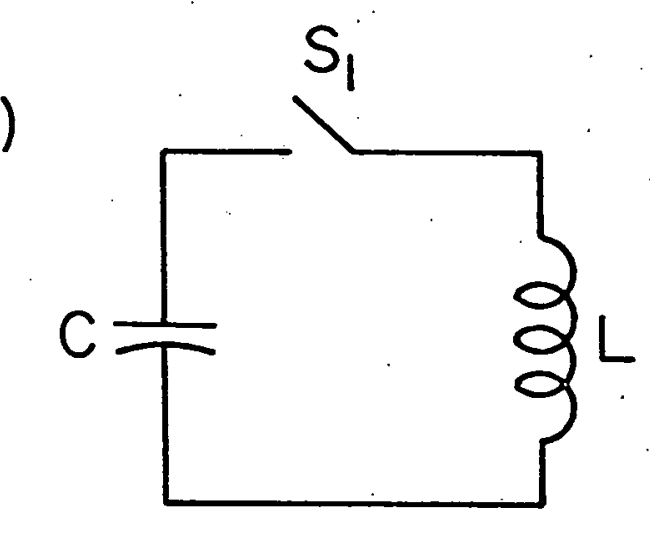

NORMAL OPERATION

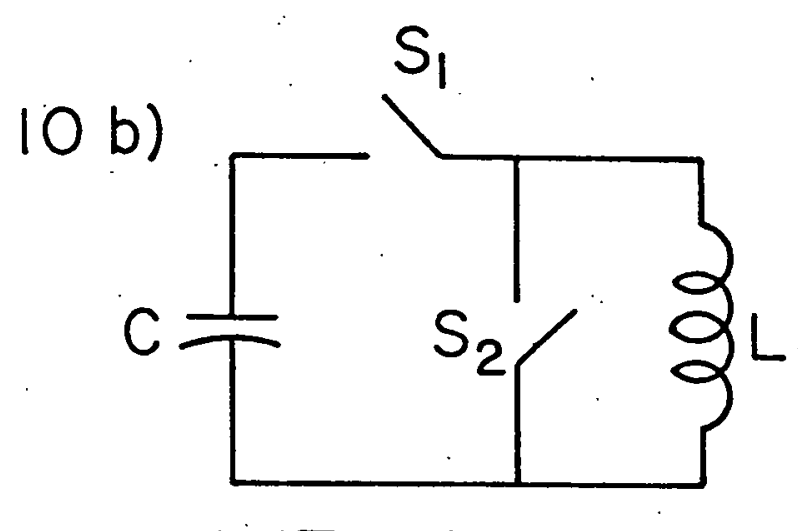

WITH CROWBAR
$S_{1}$ closes

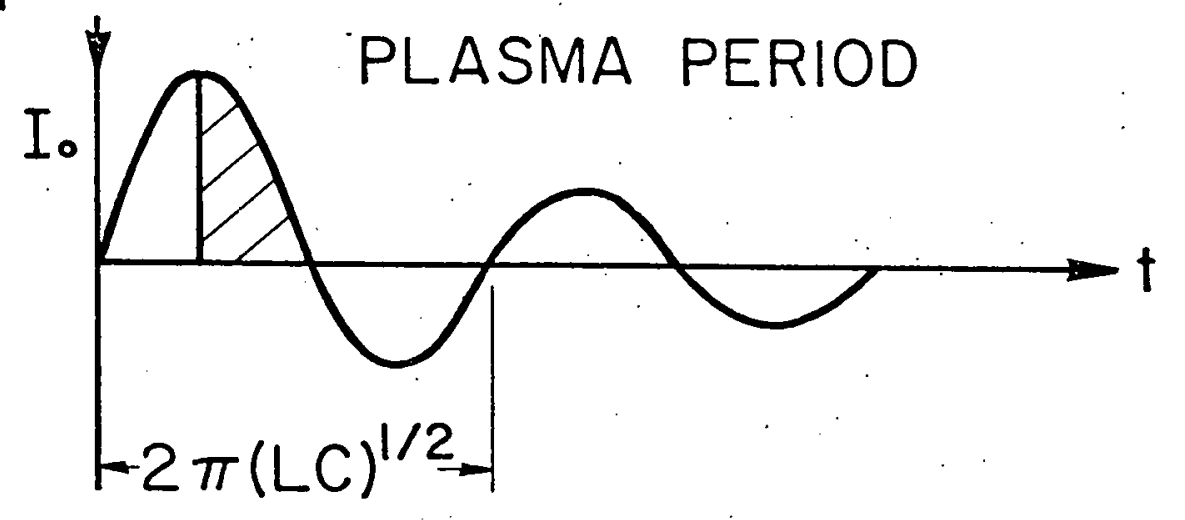

$S_{1}$ closes

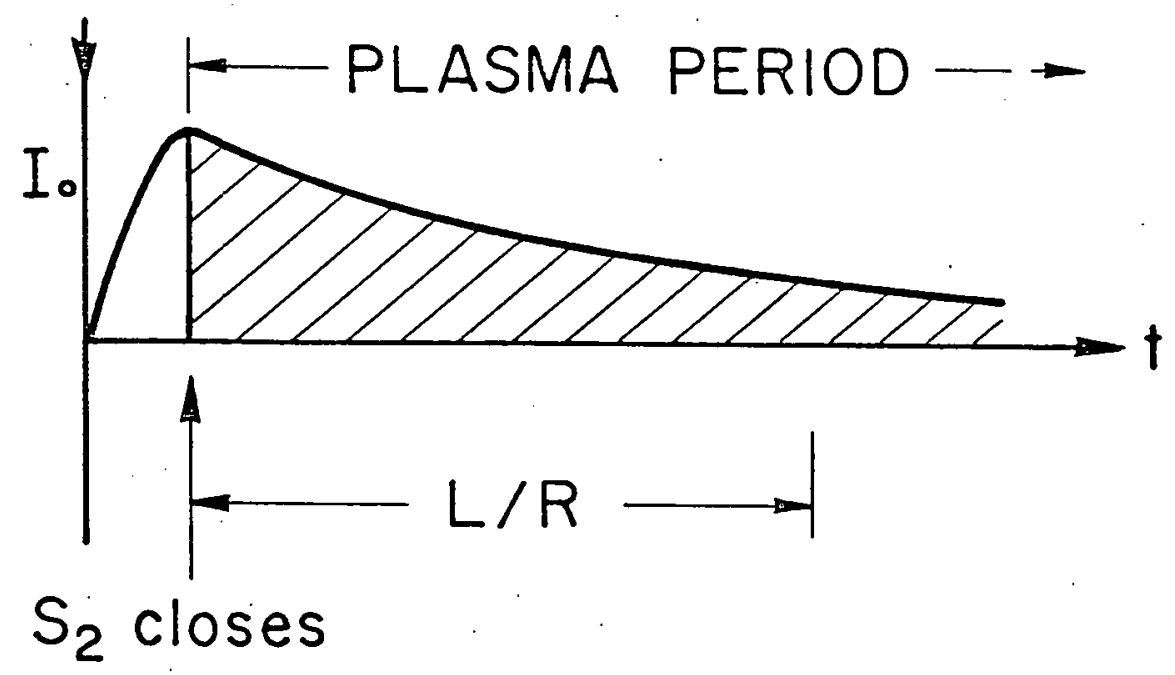

Fig. 10: Effect of Crowbarring 
TABLE III

HIGH ENERGY NEUTRON EXPOSURE REQUIRED TO STUDY DIFFERENT PHENOMENA.

\begin{tabular}{|c|c|c|}
\hline & $\begin{array}{l}\text { APPROXIMATE } \\
\text { FLUENCE (N/CM }{ }^{2} \text { ) } \\
\text { FOR MEANINGFUL } \\
\text { WORK }\end{array}$ & $\begin{array}{l}\text { HICIIP } 3 \\
\text { DT PIULSES }\end{array}$ \\
\hline Transmutation Reactions & $>10^{10}$ & 1 \\
\hline SuRface Studies & $10^{16}$ & $1-10$ \\
\hline กefect Studies & $10^{16}-10^{17}$ & $10-100$ \\
\hline $\begin{array}{l}\text { MICROSTRUCTURAL } \\
\text { COMPARISON }\end{array}$ & $10^{19}-10^{20}$ & $10^{3}-10^{4}$ \\
\hline $\begin{array}{l}\text { INITIAL SCREENING FOR } \\
\text { MECHANICAL PROPERTIES }\end{array}$ & $10^{21}$ & $10^{5}$ \\
\hline $\begin{array}{l}\text { DESIGN DATA FOR } \\
\text { MECHANICAL PROPERTIES }\end{array}$ & $10^{22}+$ & $>10^{6}$ \\
\hline
\end{tabular}


where $f_{n}$ is the total neutron fluence through the sample per HCP pulse. The minimum decay rate detectable for good statistics is rought $1 \mathrm{y} 10^{2} / \mathrm{sec}$. Therefore the required fluence through the sample is

$$
f_{n} \geq \frac{R_{\min } \tau_{1 / 2}}{P_{[n, p]}} \simeq 6 \cdot 10^{8} \text { neutrons/pulse sample }
$$

If the sample area is $1 \mathrm{~cm}^{2}$ and is placed $2 \mathrm{~cm}$ away a yield of $3 \cdot 10^{11}$ neutron/pulse would be required. As can be seen in Table. II, this may be achievable in HICUP 1 with DT fuel and without crowbarring. By putting the proper neutron reflectors behind the sample it should be possible to. simulate the precise neutron energy spectrum predicted in fusion reactors (Fig. 7), and these macroscopic reaction rate studies would be valuable for lst wall modeling studies using computer codes to predict the wall. life.

Thus the study of the neutron damage processes, particularly void swelling, requires a materials testing facility or FERF for a successful fusion reactor program. An inexpensive candidate for such a FERF for at least some of these materials studies is a hypocycloidal pinch and at the University of Illinois we are designing and preparing to construct just such a device. 


\section{REFERENCES}

1. B. Badger, et a1., "UWMAK-I, A Conceptual Tokamak Power Reactor Design, "Nuclear Engineering Dept., University of Wisconsin, Report UWFDM-68, Vol. I, 1974.

2. G. H. Miley, A. B. Chilton, S-Y Chen, R. L. Miller, and G. Fenske, "Studies of a Mirror Facility for Radiation Testing of Materials Prometheus," Proc. of International Conf. on Radiation Test Facilities for the CTR Surface and Materials Program, July $75-18,1975$, ANL ANL/CTR-75-4, p. 726.

3. D. R. 01 ander, "Fundamental Aspects of Nuclear Reactor Fuel Elements," Technical Information Center, Dffice of Public Affairs, EP.DA TID-26711-P1, p. 418-518 (1976).

4. D. Okrent, et al., "Lecture Background Notes on Fast Reactor Fuel Element Behavior," Argonne National Lab., August 1976, p. 5-4.

5. B. L. Eyre, W. M. Lomer, and R. S. Nelson, "Design of Irradiation Experiments for Fusion Reactor Materials, "Proc. of International Conf. on Radiation Test Facilities for the CTR Surface and Materials Program, July 15-18, 1975, Argonne National Lab., AML/CTR-75-4, p. 123 .

6. They are: Prof. J. C. Glowienka, Prof. G. Gerdin and Prof. F. H. Southworth.

7. J. H. Lee, D. R. McFarland and F. Hoht, "Production of Dense Plasmas in a Hypocycloidal Pinch Apparatus," The Physics of Fluids, Vol. 20, p. 313 (1977).

8. N. A. Krall and A. W. Trivelpiece, Principles of Plasma Physics, McGraw-Hi11, New York, 1973, p. 123-128.

9. 0. Zucker, W. Bostick, R. Gullickson, J. Lonin, J. Luce, and H. Sahlin, "A Repetitiveiy Pulsed Material Testing Facility," Proc. of International Conf. on Radiation Test Facilities for the CTR Surface and Materials Program, July 15-18, 197.5, Argonne National Lab., ANL/CTR-75-4, p. 483.

10. M. M. Cohen and K. M. Zwi isky, "ERDA Neutron Source Program," Ibid. p. 11. 